\title{
6. Measuring Progress: The International Context
}

\author{
Brian Pink, Sue Taylor and Hannah Wetzler
}

\section{Introduction}

Progress is an idea that echoes and has echoed throughout societies across the world. The idea of progress and what it means has influenced how societies and nations understand themselves, how they change over time, and how they relate to other nations.

The idea of progress as societal improvement has a long history. Notions of national or societal progress can be traced back to early civilisations, and were discussed by the early philosophers including Aristotle and Socrates. More modern ideas around progress were further developed throughout the Reformation and the Industrial Revolution. In the nineteenth century, for example, political economist John Stuart Mill wrote about the importance of including the environment, rather than simply wealth or growth alone, in understanding national progress and he noted the importance of people developing their capabilities in order to achieve higher levels of happiness (Mill: 1848). More recently, in the twentieth century and early part of the twentyfirst, as the world underwent several major economic and societal upheavals, the understanding and measurement of progress developed further, shaping how we understand it today.

This chapter paints a brief history of the development of progress measurement during the twentieth and twenty-first centuries. It examines the key events that influenced understandings of progress - such as the two World Wars, the Great Depression and the rise of key international organisations - and how to measure it. It looks at how the understanding of national progress has shifted from one of economic development towards one that includes societal wellbeing and environmental sustainability. The essay also incorporates a number of insights into the contributions made by Ian Castles (Australian Statistician from 19861994) in improving the statistics that inform on progress. The chapter looks at key national and international developments in the early 2000s and those following the release of the Stiglitz-Sen-Fitoussi report, and highlights the work that the Australian Bureau of Statistics has undertaken as a key player in the international statistical community. It concludes with a brief review of future international work, which will further shape how the world understands and measures progress. 


\section{Changing ideas of progress through the twentieth century}

Throughout the twentieth century, economic development was a key goal for governments across the world and as a result, perhaps the most common lens through which national progress is understood. This section of the chapter charts the emergence through the century of a number of different views of progress, first through the early focus on economic growth and GDP, then an explosion of interest in charting wellbeing and human development, and finally a still emerging interest in the environment and climate change.

\section{The rise of GDP}

In 1934, Russian American economist Simon Kuznets developed Gross Domestic Product (GDP) as a tool for measuring the production or income of a country. GDP aggregates the value added of all money-based economic activities. It is based on the System of National Accounts (SNA) and allows comparisons to be made over time and between countries and regions.

GDP is the best-known measure of macro-economic activity and one of the most widely used statistics (European Commission: 2009). This is largely due to its clear methodology and clarity of concept, which is easily replicated over time and between nations. Because of this, GDP is used not only as a measure of a nation's production value and economic development more broadly, but also often as a measure of progress. To cite Ian Castles, 'No single statistic has ever claimed such attention. It became a standard against which almost all aspects of economic performance were judged' (Castles: 1973).

During WWII, the Bretton Woods conference in 1944 saw many nations come together for the purpose of taking a unified, global approach to regulating international monetary and financial order. The conference resulted in the establishment of the International Monetary Fund (IMF) and the forerunner to the current World Bank. Castles noted that after the conference, 'GDP became the main tool for measuring economic progress throughout the world' (Castles: 1973).

While GDP is a valuable and powerful statistic within itself, its use and misuse has attracted criticism. Many have argued that GDP has limitations as both a measure of economic activity, and a measure of progress more broadly. However, measuring a nation's welfare or progress using GDP was never developer Kuznets's intention for GDP; he stated 'the welfare of a nation can scarcely be inferred from a measure of national income' (Kuznets: 1934).

In Australia in 1973, Ian Castles produced the essay 'Economic Growth: Is it worth having?' that called into question the idea of looking at national progress 
through the lens of economic growth alone. Castles said that economic growth should not be pursued for its own sake, but should be the result of policies directed to improving the welfare of the community without using resources wastefully. In his essay, Castles also recognised that people have different values, and therefore what some may consider progress, others would see as regress. Castles' work articulated what many others around the world were beginning to recognise, and what John Stuart Mill had noted a century earlier: that there are factors beyond economic development that are important to a nation's wellbeing.

\section{The rise and rise of social statistics}

The latter half of the twentieth century saw enormous interest in the concept of wellbeing and in issues of social concern as evidenced by: the establishment of the United Nations; enormous growth in the number and range of social statistics emerging from the Social Indicators Movement of the 1960s and 70s; and the emergence of important international initiatives such as the Human Development Index in 1990, and the Millennium Development Goals in 2000.

\section{The establishment of the United Nations}

A major international post-World War II development was the establishment of the United Nations. The United Nations supplanted the previous League of Nations, which was set up after the First World War as a forum for international cooperation. Many other nations have since joined the United Nations and it currently has 193 member states. In 1948, the United Nations General Assembly developed the Universal Declaration of Human Rights, which outlines a range of rights seen as fundamental for all people. Examples include Article 23, which addresses the right to employment in a safe and prejudice-free environment; Article 24, which addresses the right to rest and leisure; and Article 25, which addresses the right to an adequate standard of living. These universal rights have served to help frame understandings of national progress, providing aspirations for people and their quality of life.

\section{Social Indicators movement}

During the 1960s and 70s, international interest grew in how to come to grips with the scope of social statistics and how summary measures might be constructed. In 1969, the UN Declaration on Social Progress and Development attempted to document the international consensus on the meaning of progress at that time. The declaration sets out in detail the rationale, principles, objectives and means to achieving societal progress. In the declaration, the UN identified main goals for social progress and development around areas such as work life, hunger and poverty, health, education and literacy, housing and services (ABS: 2005). 
At the same time, many statistical agencies began to consider how to measure societal wellbeing. In the 1960s, Raymond Bauer developed a set of Social Indicators. These were a collection of measures that aimed to assess national wellbeing by looking at the social conditions of society; '[they are] statistics, statistical series, and all other forms of evidence that enable us to assess where we stand and are going with respect to our values and goals' (Bauer: 1966). The idea of social indicators was taken up by statistical agencies around the world.

In Australia, the ABS published its first set of Social Indicators in 1976, which brought together a wide range of topics, in a single report, with the specific purpose of analysing key social issues in Australia (ABS: 1976). In 1994, in a prescient move, Ian Castles, then Australian Statistician, replaced the Social Indicators Report - which was struggling to keep up with the ever-expanding set of data available from the Bureau's social surveys - with Australian Social Trends (ABS: 1994). This publication continues to this day and has built up an impressive archive of articles across a wide range of social issues. It presents statistical analysis and commentary on a wide range of current social issues, bringing together data from many sources to tell a story about Australian life. In the preface to the first issue, noting the importance of analysing social trends, Castles wrote that 'an examination of social trends tells us not only where we are now and where we have come from, but also where we are headed' (ABS: 1994).

\section{The Human Development Index}

In 1990, the United Nations Development Program (UNDP) produced the first Human Development Index (HDI), based on the Nobel prize-winning work of Amartya Sen. The index aimed to measure progress towards human development, between countries and over time, by looking at what the UNDP considered essential dimensions of quality of human life; health, education and income. Importantly, the HDI provided an alternative to the then conventional assessments of progress.

The current index compiles composite data on national levels of life expectancy, both mean years of schooling and expected years of schooling, and gross national income per capita (at Purchasing Power Parity US\$). It uses this to give an annual rank to each country based on whether people in their countries are achieving 'a long and healthy life (health), access to knowledge (education), and a decent standard of living (income)' (UNDP: 2012). More recently, the UNDP has complemented the HDI with an inequality-adjusted human development index (IHDI), which takes into account inequality between people within the nation across the three HDI dimensions.

The work of the UNDP has drawn criticism over the years. Perhaps most notably, in 1999 Ian Castles critiqued the statistical methods used by the UNDP in their reporting of data in the Human Development Report (UN Statistical Commission: 
2001). He emphasised the importance of the independence, objectivity and integrity of statistical work for public policy, especially at the international level. Castles criticised the methods and accuracy of key data in the report, including the HDI, because of its composite nature and the implicit assumptions in its weighting system. He also argued that the UNDP should use real GDP per capita (PPP\$), instead of GDP per capita (US\$) (UN Statistical Commission: 2001). An Australian delegation (led by Mr Bill McLennan) ensured that these and other concerns were considered by the UN Statistical Commission, which ultimately led the UNDP to take steps to improve the accuracy of the Development Report.

The HDI itself has drawn criticisms for not taking into account the impacts that human development has on the environment, although there are currently plans underway to start exploring how the HDI might consider incorporating sustainability. The HDI has also been criticised for not considering other aspects of society regarded as important for human wellbeing, such as spiritual and moral needs, community and relationships.

Despite these criticisms, the UNDP Report and the HDI have demonstrated that there was a huge disparity between countries in human development, in areas such as national and per capita income, in health and life expectancy outcomes and in education. High ranking nations were seen as developed, while low ranking nations were seen as developing, and world leaders began to become more concerned with the gap between developed and developing nations.

\section{The Millennium Development Goals}

In the year 2000, the United Nations Millennium Summit marked the genesis of the Millennium Development Goals or MDGs. Building on a decade of major United Nations conferences and summits, world leaders from across the world signed up to the Millennium Declaration, which committed their nations to a global partnership to reduce extreme poverty. Out of the Declaration was born the official list of eight Millennium Development Goals, accompanied by 21 targets and 60 indicators, which served as an international tool for measuring progress towards development.

The MDGs have drawn criticism. Some of the criticisms they acknowledge and address are: that the goals are too focused on global targets, and have overlooked national circumstances and differences in initial conditions (this is particularly true of progress being made in some African countries); the broad, simple nature of the MDGs overlooks a number of other factors considered important, such as social protection and security, peace and human rights, inequality and violence against women; that the framework itself does not account for vulnerabilities to natural hazards and other external shocks; the framework provides little guidance for means to achieve the targets; and several of the goals and targets 
were defined imprecisely, thereby weakening accountability for the promised international support for implementing the MDG framework (UN System Task Team: 2012).

The UN System Task Team notes that 'Critics have argued that a number of these shortcomings could have been avoided if a more inclusive consultation process had taken place in formulating the MDGs.' (UN System Task Team: 2012).

In spite of these criticisms and problems, the MDGs 'simplicity, transparency and multidimensionality helped rally broad support for the goals and their achievement, and the emphasis on human development shifted policy attention well beyond the economic growth objectives that dominated previous agendas' (UN System Task Team: 2012). They have helped shaped international understandings of progress, framing progress around poverty and human development.

\section{Environmental wellbeing}

Towards the end of the twentieth century the environment emerged as an increasingly important aspect of life to people, nations and indeed globally. While the environment has been valued for millennia, either for its importance to human society or for its intrinsic value, valuing the environment and its health in a policy sense did not gain momentum until the latter half of the twentieth century.

A number of major international initiatives focused attention on the role of the environment for global progress. In 1992, the Earth Summit: the UN Conference on Environment and Development was held in Rio De Janeiro, Brazil. From this conference came Agenda 21, which set out a plan of action for developing and measuring progress in sustainable development. Since then, statistical agencies have begun to take environmental progress and sustainability into account when considering the progress of nations overall.

\section{New views of progress for the new millennium}

The new millennium saw the development of broader overarching ways to view and measure progress and wellbeing. This section of the chapter charts these new developments, highlighting some of the key initiatives underway among a plethora of activity, including the innovative Measures of Australia's Progress. 


\section{Measures of Australia's Progress}

In 2002, the Australian Bureau of Statistics became the first national statistical agency to produce a broad-focused measuring tool for assessing national progress, developing what was then known as Measuring Australia's Progress (now Measures of Australia's Progress or MAP; ABS: 2002). MAP was developed to help Australians assess whether life in Australia is getting better.

MAP was a watershed. While the ABS had previously produced separate sets of indicators to measure economic and then social progress through the System of National Accounts (ABS: 2010-11) and the development of social indicators, MAP brought together for the first time a compendium of indicators on key aspects of society, the economy and the environment to help answer the question - Is life in Australia getting better?

As the first national statistical agency to produce a diverse collection of national progress indicators, MAP generated significant international interest and in many ways set the standard for other nations to think about the ways in which they can measure their own progress. In 2003, then Australian Statistician Dennis Trewin topped the society category of The Bulletin's Smart 100 awards for this work.

Since the first release of MAP, national and international interest in measuring progress has accelerated and a number of key initiatives are listed below.

\section{OECD Global Project on Measuring the Progress of Societies}

The OECD has made measuring wellbeing and progress across member countries a key priority for over a decade. Its work in measuring progress has accelerated throughout the 2000s. Building in part on the MAP initiative, the OECD, in partnership with a range of other international institutions, established a Global Project on Measuring the Progress of Societies in 2004 and has since hosted four major international dialogues and debates on measuring societal progress, which have set out a range of directions for global progress measurement. The OECD has more recently undertaken a number of major initiatives and these are discussed in the Stiglitz-Sen-Fitoussi section of the chapter below.

\section{Treasury Wellbeing Framework}

In the early 2000s, the Australian Treasury developed the Treasury Wellbeing Framework to guide its policies (The Treasury: 2011-12). The Treasury Wellbeing Framework is a qualitative framework that operates to facilitate an objective and thorough analysis of policy options for improving wellbeing. It identifies five dimensions that directly or indirectly have important implications 
for wellbeing, and are particularly relevant to Treasury. The dimensions do not provide a simple checklist: rather their consideration provides the broad context for the use of the best available economic and other analytical frameworks, evidence and measures. The Treasury also point out that the trade-offs between and within the dimensions need to be considered. The five dimensions of the Wellbeing Framework include the set of opportunities available to people, the distribution of those opportunities, sustainability of opportunities, overall level and allocation of risk borne by individuals and the community, and complexity of choice facing individuals and the community.

\section{Hong Kong Quality of Life Index}

The Chinese University of Hong Kong first published the Hong Kong Quality of Life Index in 2003 (The Centre for Quality of Life: 2012). The index aims to track the quality of life for the people of Hong Kong, providing policy makers and the community with a useful reference tool. This in turn aims to help make improvements in the wellbeing of the people of Hong Kong. Now an annual product, the index is a composite of statistics, which report on societal, economic and environmental wellbeing. The index uses 21 indicators from a variety of data sources, such as national statistics (e.g. unemployment rates and GDP), as well as subjective data from surveys (e.g. people's satisfaction with the government).

\section{Monitoring Sustainable Development in Switzerland}

Also in 2003, the Swiss Federal Statistical Office, together with other Swiss government departments, produced Monitoring Sustainable Development in Switzerland (also MONET, see Swiss Federal Statistical Office: 2010). The purpose of MONET is to assess whether Switzerland is 'on the road to sustainable development', by regularly reporting on the status and progress of the nation's sustainability.

MONET draws on 80 indicators (though in its simplified form it consists of 16 broad indicators), which focus on four areas:

1. Meeting needs: how well do we live;

2. Preservation of resources: what are we leaving behind for our children?

3. Decoupling (efficient use of resources): how effectively are we using our national resources?

4. Fairness: how well are resources distributed?

The indicators are presented side by side, using a traffic light approach so that people can see clearly whether progress is being made in these areas. 
MONETs approach to progress through the lens of sustainability has influenced other agencies, such as Statistics New Zealand's Measuring New Zealand's Progress Using a Sustainable Development Approach. It has also helped shape thought around national progress in terms of how well a nation is promoting the current needs of its people, without compromising the needs of future generations.

\section{The Happy Planet Index}

In 2006, the new economics foundation (nef) in the UK, recognising the importance of sustainability to national progress, produced the Happy Planet Index, which took into account how well a country can achieve wellbeing sustainably (nef: 2010). The Happy Planet Index ranks nations according to how well they are doing in terms of supporting their people to live long and happy lives, while ensuring that future generations can do the same. It combines environmental impact with wellbeing to assign each country with an index, based on three measures:

- Subjective life satisfaction;

- Life expectancy at birth; and

- Ecological footprint per capita.

When it was first released, the Happy Planet Index generated huge media attention and was signalled by some as a way of comparing the true conditions of nations (nef: 2010).

\section{Gross National Happiness Index}

Another development to attract much international attention was the Gross National Happiness Index (GNHI). Developed in 2007 by the Centre for Bhutan Studies, this approach heralded a new way of thinking about progress, by focusing on the effect of growth on societal happiness and wellbeing. GNH looks at national progress in terms of advancing the happiness of its citizens, rather than the performance of the economy.

While the initial thinking around the GNHI has antecedents in the 1970s, the idea of happiness as a national goal in Bhutan can be traced back even further. A legal code from 1729 declared 'if the Government cannot create happiness (dekid) for its people, there is no purpose for the Government to exist' (Ura et al: 2012). In the 1970s, the idea further materialised: then King Jigme Signye Wangchuck, observing the detrimental effect of economic development on the cultural fabric of other nations, proposed measuring progress in terms wider than economic development. He declared that happiness was more important than GDP and, since then, the nation has oriented its national policy and development plans towards achieving Gross National Happiness. 
In 2007, the Centre for Bhutan Studies developed this idea into a measurement of Bhutan's progress. The index uses objective and subjective responses to the Gross National Happiness Survey, which asks questions that look at whether both material and spiritual, emotional and cultural needs are being met. While this has attracted perhaps unwarranted criticism for being narrow in focus on happiness, the Centre for Bhutan Studies has responded by claiming that GNHI is an all-encompassing measure that covers a range of areas that affect the nation's wellbeing (Ura et al: 2012). The GNH index is currently linked with a set of policy and program screening tools that have a direct impact on the national policies that affect wellbeing.

Bhutan's latest index was launched at the fourth World Forum in Delhi in October 2012, and received widespread coverage including a feature article in Time magazine.

\section{Measuring New Zealand's Progress Using a Sustainable Development Approach}

In 2009, Statistics New Zealand released its report Measuring New Zealand's Progress Using a Sustainable Development Approach (Statistics New Zealand: 2009). Their approach was to look at national progress through the lens of sustainability, asking the question: 'How is New Zealand progressing towards or away from sustainable development?' The approach closely follows that of Switzerland's MONET initiative. The most recent update presents 16 indicators, which aim to answer four key questions:

1. How well do we live?

2. How well are resources distributed?

3. How efficiently are we using our resources?

4. What are we leaving behind for our children?

\section{Canadian Index of Wellbeing}

Another well-known wellbeing initiative is the Canadian Index of Wellbeing, which aims to 'measure what matters' most to Canadians (see Michalos et al: 2011). It is supported by the Canadian Index of Wellbeing Network, an independent, non-partisan group of national and international leaders, researchers, organisations and citizens. A key feature of this index is that it was developed from the ground up after a very widespread consultation with Canadians, in contrast to many other initiatives, which tend to have a top-down approach. It claims to be the only national index that measures wellbeing in Canada across a wide range of domains and draws attention to the interconnections between domains. The index is a series of composite indicators, with an index for each of 
its eight domains as well as an overall index. It uses an array of data taken from survey responses and national data. Data was initially released in 2009, with the complete product released in 2011 .

\section{Beyond GDP Initiative}

In 2007, the European Commission, together with the European Parliament, Club of Rome, OECD and WWF, hosted the high level conference Beyond GDP. The conference focused on clarifying measures of progress, considering which indicators would be best to accurately measure progress beyond GDP. From this, they launched the Beyond GDP Initiative, which aims to improve the measures of social, economic, environmental progress, wealth and wellbeing. The initiative aims to share important information on recent developments and ongoing work in this area.

In 2009, the European Commission released the report 'GDP and beyond: Measuring progress in a changing world' (European Commission: 2009). The report contained a roadmap which outlined five actions to improve measures of progress:

1. Complementing GDP with environmental and social indicators;

2. Near real-time information for decision-making;

3. More accurate reporting on distribution and equalities;

4. Developing a European sustainable development scoreboard for measuring progress in sustainability;

5. Extending national accounts to environmental and social issues.

\section{A watershed: The Stiglitz-Sen-Fitoussi report}

Public interest in the interrelationships between economic, social and environmental aspects of life has continued to grow in communities, in governments, and internationally. The map (see Figure 1) provides an indication of the plethora of international indicator activity involved in measuring wellbeing, societal progress and sustainable development that has occurred or is currently underway.

One of the most notable developments listed on the map of initiatives is the Stiglitz-Sen-Fitoussi report which has added considerable impetus to progress measurement initiatives across the world since its release. The Commission on the Measurement of Economic Performance and Social Progress was established in 2008 by then French President Nicolas Sarkozy who was concerned that 
the existing measures of capturing and comparing national progress were inadequate. The Commission was led by Professor Joseph Stiglitz as its chair, with Professor Amartya Sen as chief advisor and Professor Jean-Paul Fitoussi as its coordinator, and included 19 other economists, social and political scientists, psychologists and statisticians.

The purpose of the Commission was to:

- identify the limits of GDP as an indicator of economic performance and social progress, including the problems with its measurement.

- consider what additional information might be required for the production of more relevant indicators of social progress, and

- assess the feasibility of alternative measurement tools, and to discuss how to present the statistical information in an appropriate way.

In 2009, the Commission published a report which underlined the need to understand societal progress beyond economic development. The Commissioners pointed out that while economic indicators are not sufficient measures of progress, they are not within themselves wrong, they are wrongly used. They argued that GDP is not a measure of wellbeing, and that other economic, social and environmental dimensions should be taken into account. They concluded that 'the time was right to shift emphasis from measuring economic production to measuring people's wellbeing' (Stiglitz et al: 2009).

The Stiglitz-Sen-Fitoussi report outlines thirty recommendations for improving measures of national progress. These included improving a number of traditional economic measures, measuring components of quality of life and emphasising the importance of data about improvements in sustainability. The report received huge international attention, especially from NSOs, who saw its recommendations as instruction for rethinking how to measure progress, and how they could improve their own methodologies.

The release of the report occurred at around the time of the Global Financial Crisis (GFC). The authors described the GFC as one of the worst financial, economic and social crises in history. They argued that the crisis took many economic analysts and government officials by surprise because the measurement systems used to measure and monitor the economic performance across nations failed. The main measurement systems, in the years prior to the crisis, suggested that the economy was doing far better than it was. In their opinion, this was largely due to the questionable assessments of the economic performance of the financial sector, and the limits and misuse of GDP as a measure of national economic performance. They argued that had measures which included economic sustainability (such as income indebtedness) been used, they would have revealed a more cautious 
view of economic performance. They argued that the excessive focus on GDP metrics - and a failure to understand the limitations of that measure - meant that alternative statistics were not given the prominence they deserve.

In a sense, many of the ideas presented by the Commission were not new. As demonstrated earlier in this chapter, many critics (such as Ian Castles) had already challenged the idea of relying solely upon economic growth to understand progress. Some countries, including Australia, were already reporting on broader measures of national progress.

Neverthertheless, the Commission brought together many new and existing ideas and suggested a number of recommendations for statistical agencies all over the world to take on board. In particular, it recommended a rethink of measurement systems and encouraged a national and global dialogue on what we care about, whether what we are striving for is achieving what we care about, and whether this is adequately reflected in our national and international metrics. Around the world, many statistical agencies and organisations responded enthusiastically to the Stiglitz-Sen-Fitoussi report. Some used its recommendations to improve their existing measures of progress, while others used it to develop new approaches to progress measurement. The key post-Stiglitz initiatives are listed below. 


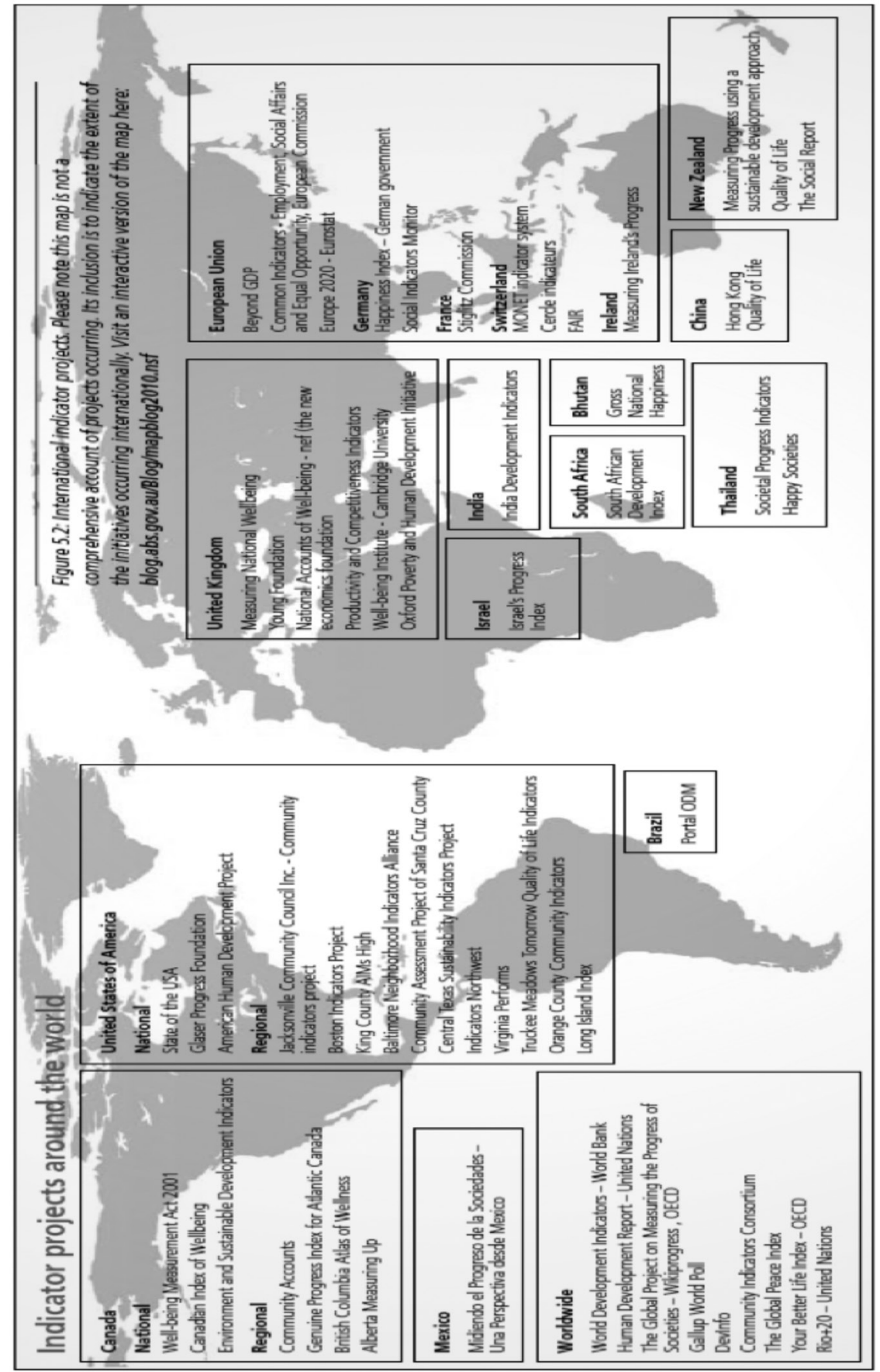

Figure 1 International map of progress initiatives

Source: ABS: 2012a. 


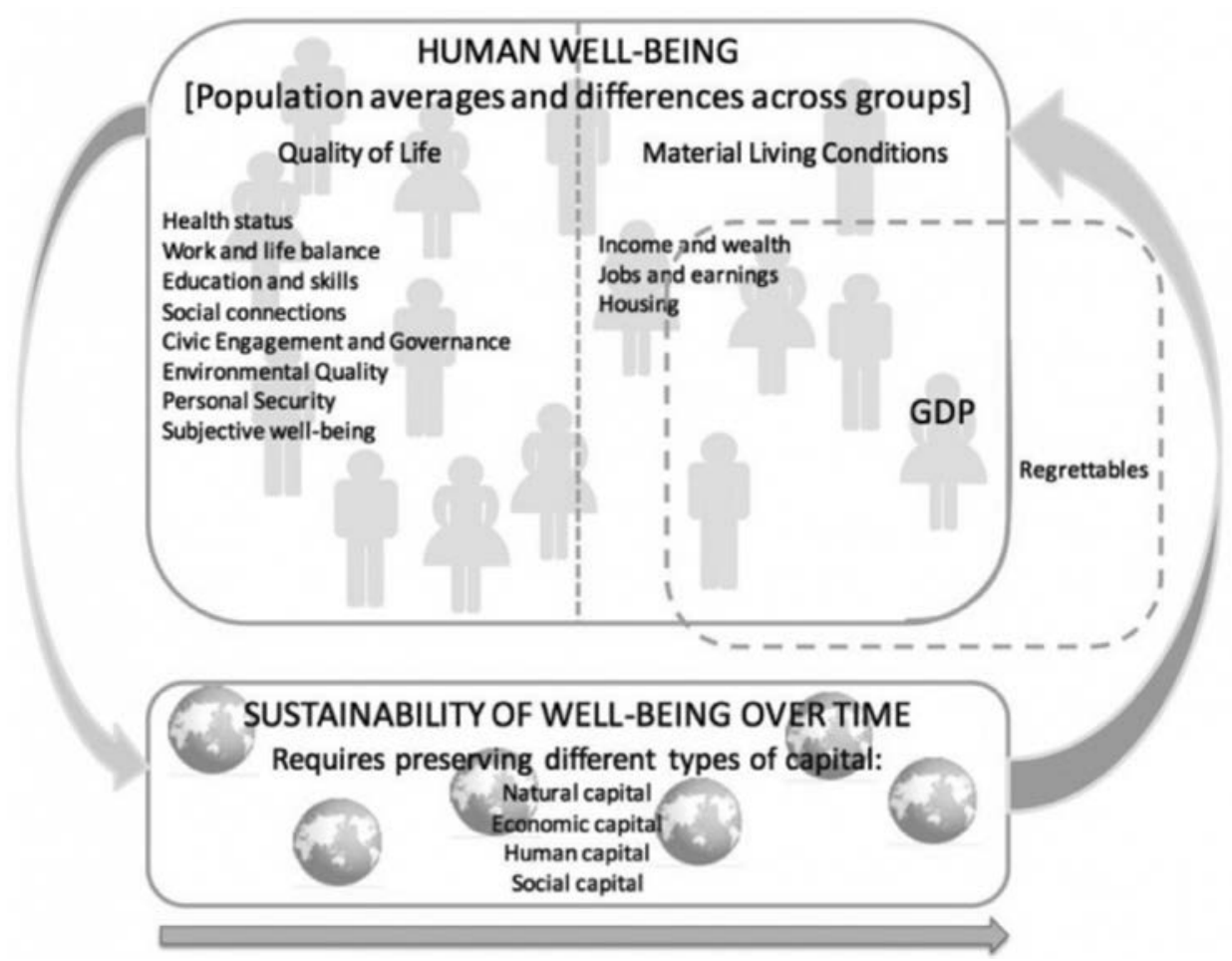

Figure 2 The OECD 'How's Life?' framework for measuring wellbeing and progress

Source: OECD: $2011 \mathrm{~b}$.

\section{OECD Better Life Index}

In 2010, the OECD established the online forum Wikiprogress, where people can share information and developments on measuring progress. Then in 2011, the OECD released the first Better Life Index, an online interactive tool for comparing wellbeing across nations (OECD: 2011a). This was accompanied by the How's Life report, which focused more specifically on the wellbeing of nations by looking at progress across various areas (OECD: 2011b). These initiatives are centred on individual wellbeing and track the improvement of people's lives over time. They organise indicators under two major domains: material living conditions and quality of life (see Figure 2). Complementary to these domains is a third - Sustainability of wellbeing over time - although this domain is currently outside the scope of the Better Life Index.

\section{Measuring National Wellbeing, UK}

In 2010, British Prime Minister David Cameron asked the Office of National Statistics (ONS) to measure national wellbeing as a basis for the development 
of new policy. As a result, the ONS has developed the Measuring National Wellbeing initiative, aimed at capturing people's wellbeing, the performance of the economy and the quality of the environment (see Office of National Statistics 2011). The ONS has undertaken a variety of approaches to determine what it is that is important to measure. In 2010-11, a national debate was held on "What matters to you?" People were able to participate in this debate through an online survey, face-to-face events and other activities.

The ONS received strong support throughout the consultation for a number of key themes important in the measurement of wellbeing. The ONS published their proposed domains and measures for measuring national wellbeing in 2012 and outlined the milestones and results to date of the ONS Measuring National Wellbeing Program. The proposed domains are: individual wellbeing, our relationships, health, what we do, where we live, personal finance, education and skills, governance, the economy, and the natural environment.

As an additional part of their Measuring National Wellbeing initiative, the ONS has been developing experimental subjective wellbeing estimates from a set of questions incorporated into their large scale Integrated Household Survey. The four questions monitor different aspects of subjective wellbeing. The survey asked respondents to rate their satisfaction in life, feelings of happiness and anxiety, and to what extent people feel the things they do are worthwhile. As subjective wellbeing is currently being considered an increasingly significant aspect of wellbeing, the ONS has been seen as a world leader in pioneering this currently experimental work.

\section{New Zealand Treasury Living Standards framework}

NZ Treasury see their role as working for the higher living standards of New Zealanders, thus improving economic performance to raise living standards. In 2011, New Zealand Treasury developed a Living Standards Framework with the intention of providing government ministers with robust, theoretically grounded and evidence-based advice that aims to improve the lives of all New Zealanders (New Zealand Treasury: 2011). They acknowledge that there are other living standards that are important in addition to material ones.

\section{Oxfam Humankind Index}

Oxfam Scotland recently undertook a national consultation to develop the Oxfam Humankind Index, first published in 2012. The Oxfam Humankind Index aims to assess Scotland's prosperity through holistic and representative measures of progress, taking into account what really matters to the people of Scotland (Oxfam Scotland: 2012). Like the ABS and the ONS, Oxfam Scotland has undertaken a consultation with the public to develop the index. Their aim 
is for policy makers and the community to use the index to make informed decisions based on the aspirations of the people of Scotland - whether they relate to their own wellbeing, the economy, governance or the environment.

\section{The Australian National Development Index (ANDI)}

The Australian National Development Index (ANDI) is a partnership of 40 leading community organisations, church groups, businesses, and universities which aims to create a national development index (ANDI: 2012). Still in development, the index aims to present a holistic measure of national progress and wellbeing that reflects the views of Australians.

Modelled on the Canadian Index of Wellbeing, ANDI's national progress measurement will be informed by the goals and values identified by a bottom-up approach that will be based on national consultation and research. It is expected to address progress domains, including children and young people, work and work life, environment and sustainability, and justice and fairness.

ANDI aims to work closely with the ABS and to support and complement the MAP project. For example, the results of the MAP consultation (see below) will inform the ANDI consultative work, while the ANDI consultative work will be considered as part of the ongoing evolution of MAP. The ABS has provided statistical guidance to ANDI (and included ANDI in the MAP consultations). However, the ABS is cautious to be involved with, or to produce, an index of progress. Indexes can be problematic. They are over simplistic; reducing the complexity of progress made across different domains, where progress or regress can occur, to a single number. Indexes also pose methodological issues, such as the difficulties in weighting and combining indicators from different domains (for example, how do you weight and add together progress in household income with progress in preserving threatened species, with progress in social inclusion?).

\section{How has the ABS been developing progress measurement?}

\section{Measures of Australia's Progress dashboard}

In 2010, the ABS relaunched Measures of Australia's Progress, for the first time in an entirely electronic format, and incorporating a dashboard of key social, economic and environmental headline indicators to improve accessibility and visibility and help people, at a glance, to assess whether some key aspects of 
life in Australia are getting better (see Figure 3). In this way, readers can review progress across the social, economic and environmental domains and understand the issues unique to each.

The dashboard approach encourages readers to consider the indicators and make their own assessment of whether Australia is, on balance, progressing and at what rate. In using a dashboard approach, the ABS has avoided the complexity and contestability of a comprehensive accounting system, which is complicated to both compile and interpret, and the potential oversimplification involved in presenting a single progress indicator.
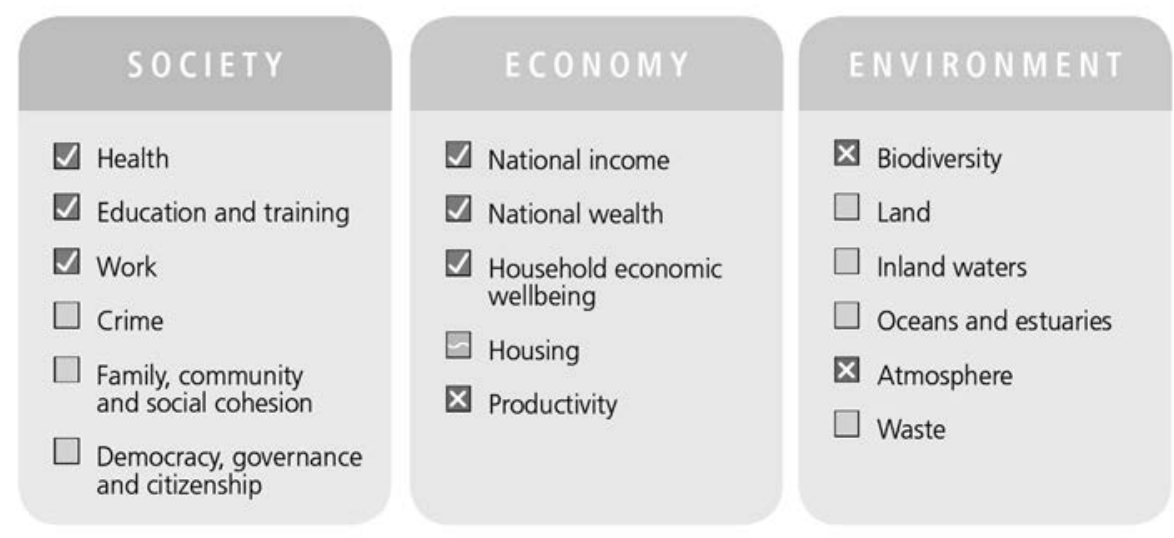

\section{Legend:}

$\square$ Progress has generally been made in this headline indicator compared with ten years ago.

$\mathbf{X}$ This headline indicator has generally regressed compared with ten years ago.

There has been no significant movement in this headline indicator compared with ten years ago.

There is either no headline indicator for this area of progress or no time series.

\section{Figure 3 Measures of Australia's Progress dashboard}

Source: ABS: 2012b.

\section{MAP consultation}

In addition to the changes introduced in 2010, almost a decade on from the first MAP release, and in light of recent international initiatives in progress measurement (most notably the Stiglitz-Sen-Fitoussi report), the ABS, guided by a MAP Expert Reference Panel, decided to undertake a national consultation to review MAP. ABS wanted to ensure that MAP remains relevant to today's society and continues to measure what Australian society cares about. The consultation was developed around the notion that if we are to know if we are progressing, then we need to know where we are headed. The consultation was therefore 
designed to ascertain from the Australian public what their aspirations were for the nation's progress. Once this had been articulated through the consultation process, the ABS would then look at the measures that might be available to inform on progress towards those goals.

The MAP consultation began in late 2010. There were several strands to the consultation, including an initial foray into the world of social media in order to engage with user groups who may otherwise be interested in the ABS and its activities, such as younger people or those who do not regularly use the ABS statistics. The ABS used various media and social media platforms, such as radio interviews, a Facebook page and, notably, a successful MAP 2.0 Blog. These provided members of the public with avenues to contribute their thoughts to the ABS on what matters most to them for the nation's progress. In order to promote the social media campaign, the ABS approached a number of prominent Australians, including Dick Smith, Michael Stutchbury, and Lauren Jackson, to contribute their aspirations about Australia's progress and these were posted on the MAP 2.0 Blog. In addition, the ABS hosted workshops across Australian capital cities, welcoming feedback from interested clients, ranging from state government stakeholders to business and community groups, and sought submissions from a range of commonwealth government agencies.

The ABS received submissions from other business and community groups and councils and examined a range of state and local government planning documents, which contained information on the goals and aspirations that guide the development of states and territories, as well as local councils. They also considered community projects, which aimed to track progress at the community level. As part of the consultation, the ABS also examined international projects being undertaken by other national statistical agencies and cross-national organisations, in order to understand how MAP fits in the broader international context.

In order to receive assistance on pulling the various consultation threads together, the ABS hosted a number of Topic Advisory Panels. These panels brought together experts from across business, community, the media, research and government sectors, and had extensive knowledge and experience in negotiating positive outcomes for the Australian public. The ABS held a number of workshops with these topic experts in order to discuss and distil the consultation feedback efficiently.

In November 2012, the ABS released the report Measures of Australia's Progress - Aspirations for our nation: A conversation with Australians about progress (ABS: 2012a). It details the consultation process undertaken by the ABS to discover what aspirations Australians have for national progress and provides an account of the consultation process and the feedback that the ABS received. It also sets out a framework of aspirations and themes, which were identified as important for measuring the nation's progress. A notable addition is that of a fourth domain, on 
governance, which received strong support through the consultation as a separate domain because of its key role as an enabler. In addition, family, community and the built environment were also identified as important to Australians.

The report marks the end of the ABS's active consultation with the Australian public, although as MAP is a constantly evolving product, members of the public are still welcome to provide feedback to the ABS. Following the release of the report, the next phase will involve working with statistical experts to find indicators that match or present data relevant to the aspirations and themes identified in the new MAP framework. The new, refreshed Measures of Australia's Progress will be released in November 2013.

\section{ABS involvement in international initiatives to improve the measurement of wellbeing and progress}

In addition to its work in improving the conceptual understanding of what progress means to Australians, ABS is currently involved in a number of international initiatives to improve particular measures of wellbeing and societal progress, namely two OECD Expert groups relating to economic statistics and the development of a household wealth framework, and an OECD Working group developing guidelines on subjective wellbeing. The ABS has also been an early adopter of the System of Environmental-Economic Accounting (SEEA). These developments are described in more detail below.

\section{Economic statistics}

Within the ABS there has for some time been a recognition that more could be done within the Australian System of National Accounts to stress the importance of the household perspective in devising measures of living standards and progress. In 2002, the ABS introduced a range of annual analytical measures of household income, consumption, saving and wealth in order to further articulate the economic experience of the household sector within the Australian economy.

Recognising the importance of measuring inequality, and noting that simple averages tend to not be reflective of the conditions of a 'typical household', the ABS has been participating in an OECD Expert Group to produce measures of disparities between groups of households which are consistent with National Accounts income and expenditure measures. The OECD analysis will be published in the first half of 2013, and following this the ABS will be publishing the results for Australia. Both of these initiatives build on the strengths of the 
National Accounts, as a complete, integrated and coherent picture of the macro economy, and as describing the economic experience and living standards of Australians.

\section{Household wealth framework}

An international Expert Group, sponsored by the OECD and chaired by the ABS, is developing new international guidelines for compiling statistics on household wealth, and a comprehensive and integrated framework for statistics on household income, consumption and wealth. The Expert Group's work is expected to be published in 2013 in two OECD publications.

The first publication will provide guidance on the collection, analysis and dissemination of household wealth statistics at a detailed level. The work will address the common conceptual, definitional and practical problems that countries face in producing these statistics, and will improve the comparability of the currently available data. They will also allow statistics on household wealth to be integrated with economic wellbeing measures, such as income and consumption. Household level measures will also be comparable with broader economic measures. Harmonisation with other international standards is also an important objective of the work, e.g. the 2008 System of National Accounts, the 2011 Canberra Group Handbook on Household Income Statistics, and the recommendations of the $17^{\text {th }}$ International Conference of Labour Statisticians on household income and expenditure statistics.

The Expert Group is concurrently developing an integrated framework for the joint measurement and analysis of statistics on household income, consumption and wealth. The integrated framework will bring the new wealth guidelines together with the existing standards for household income and expenditure and will underpin the production and analysis of harmonised and coherent information on the economic situation of individual households. Such a framework is needed to support the design of better-informed government policies and better targeting of programs to assist households in need. Betterinformed policies hold the promise of delivering improved economic wellbeing to individuals, higher economy-wide performance, and better individual and societal outcomes across a range of dimensions of social concern.

The OECD Expert Group publications are expected to stand as a critical reference point for data compilers and users of household income, consumption and wealth data for some time. However, in due course and following 'road testing' by an increasing number of countries, consideration will need to be given to whether the outputs of the Expert Group should be refreshed, brought up to date with evolving practice, and then brought to the attention of other statistical bodies, such as the United Nations Statistical Commission, for possible endorsement as statistical standards. A similar process was followed in the case of the 2001 
Canberra Group Handbook on Household Income Statistics, which evolved into a standard, adopted with little modification, by the International Conference of Labour Statisticians (ICLS) in December 2003 (ILO, 2004).

\section{Subjective wellbeing}

In addition to the increasing interest in developing wellbeing measures, there has been growing interest throughout the world in developing measures of subjective wellbeing, that is, measures of how people feel and how they evaluate their lives. While once argued as being an immeasurable concept, in recent years it has been increasingly recognised that subjective wellbeing can and should be measured. Some argue that people's feelings and assessment of their own life are a true indication of a nation's progress.

The Stiglitz-Sen-Fitoussi report identified the importance of including measures of subjective wellbeing in any consideration of national progress. It recommended that statistical agencies should include both objective and subjective measures of wellbeing in their data on progress, including life evaluation, experiences and priorities.

The ABS has been collecting subjective measures of wellbeing since 1989, and has a collection spanning a variety of areas of interest across a number of surveys. The ABS has expanded its subjective measures, collecting data on overall life satisfaction, feelings of trust and safety, self-assessed physical and mental health, enjoyment in learning and work, self-assessed importance of culture and perceptions of the environment. The ABS continues to include and expand on ways to include subjective measures in its surveys.

Since 2010, the ABS has also been part of an OECD working group involved in formulating guidelines to enable national statistical organisations to consistently measure subjective wellbeing. The OECD recognises subjective wellbeing as having three components: life evaluation, affect (positive and negative) and having a sense of meaning and purpose in life. It is anticipated that the guidelines will be submitted to the OECD Committee on Statistics (CSTATS) for approval in 2013.

\section{Developments in SEEA}

In 2012, the System of Environmental-Economic Accounting (SEEA) was adopted as an international statistical standard by the United Nations Statistical Commission. Importantly, as an international statistical standard, the SEEA now has the same status as the System of National Accounts. The SEEA is a multipurpose, conceptual framework that describes the interactions between the economy and the environment, and the stocks, and changes in stocks, of 
environmental resources. Using a wide range of data, the SEEA conceptual framework provides a structure to compare and contrast information across a broad spectrum of environmental and economic issues. The development of the SEEA was driven by the desire to better understand the interactions between the economy and the environment, and to have more complete and robust information on both. This has been due to an increasing realisation that economic prosperity is dependent on the ability of the environment to supply natural resources and to absorb pollution, and that environmental policies impact on economic activity. The Stiglitz-Sen-Fitoussi report notes that:

What we measure affects what we do; and if our measurements are flawed, decisions may be distorted. Choices between promoting GDP and protecting the environment may be false choices once environmental degradation is appropriately included in our measurement of economic performance. So too, we often draw inferences about what are good policies by looking at what policies have promoted economic growth; but if our metrics of performance are flawed, so too may be the inferences that we draw. (Stiglitz et. al.: 2009)

To mark the occasion of the international adoption of the SEEA, the ABS hosted a conference 'Completing the Picture - Environmental Accounting in Practice' which aimed to assist understanding of how environmental accounts could be used and further developed in Australia. It is part of an ongoing body of work by the ABS in environmental and economic accounting, and sets out what a regular set of environmental-economic accounts might look like and how they could potentially be used.

\section{Looking forward: The future of progress measurement}

\section{Beyond 2015}

As the timeframe for the Millennium Development Goals draws to a close, the international community will direct its attention towards formulating a new set of goals. The United Nations Secretary-General Ban Ki-moon has established a High-Level Panel comprising members of civil society, the private sector and government leaders to advise him on the post-2015 agenda. He has also established a UN System Task Team to coordinate preparations for beyond 2015 and to support the work of the High-Level Panel, and requested the UN Development Group to organise country and global thematic consultations on the post-2015 agenda as input to expert and intergovernmental processes such as the High-Level Panel. Much of this work has commenced only recently, and is still in its formative stages. 


\section{Sustainable development}

Twenty years on from the 1992 Earth Summit: UN Conference on Environment and Development, nations again gathered in Rio De Janeiro, Brazil to discuss progress and commitment to a plan of action for developing and measuring progress in sustainable development. The Rio +20 Conference identified a number of sustainable development themes or priorities including poverty reduction; food security and nutrition and sustainable agriculture; water and sanitation; energy; sustainable tourism; sustainable transport; sustainable cities and human settlements; health and population; promoting full and productive employment, decent work for all, and social protections; oceans; small island developing states; disaster risk reduction; forests and biodiversity; desertification, land degradation and drought; chemicals and waste; sustainable consumption and production; mining; education; gender equality and women's empowerment; and sustainable development goals. Governance processes to take the Rio +20 outcomes forward are still being established at the time of writing this essay. However, there is emerging a strong intention that the sustainable development and post-2015 agendas should converge.

\section{OECD $4^{\text {th }}$ World Forum - reflections}

In October 2012, the ABS attended the $4^{\text {th }}$ OECD World Forum on 'Statistics, knowledge and policy' in Delhi, India. The ABS contributed four papers, sharing results and lessons learnt from our own work on measuring national progress. The ABS showcased the recent MAP consultation, our work with the SEEA framework, the household wealth framework, and some initial thinking about measurement of aspects of governance.

OECD Chief Statistician Martine Durand summarised the key messages at the close of the World Forum. She highlighted the key achievements of the OECD community in measuring progress, including reinforcement of the global momentum in measuring progress; the growing convergence in the domains people identify as important for a good life; and the common language used to discuss progress and wellbeing. She highlighted a number of remaining challenges, such as the difficulties with measuring progress in governance, social capital and cohesion, and the built environment and mobility.

She noted growing interest in understanding progress at different levels of analysis, going beyond national aggregates alone to look at data disaggregated to consider regional progress, and progress for population groups, such as gender, across the life course, and for minority groups. She suggested that building knowledge across the international community should ultimately lead to better decision making that in turn would promote change and improvements in wellbeing through a 'virtuous cycle'. 
Finally, she identified the upcoming international work for measuring progress. This includes setting an international agenda on progress goals to bring together work on wellbeing, the post 2015 agenda and the Sustainable Development Goals to create a more holistic understanding of progress.

\section{Conclusion}

Throughout the ages, nations have been interested in understanding and measuring progress. During the twentieth and early part of the twenty-first centuries, a number of major economic and societal events and the emergence of supranational institutions have been fundamental in changing the ways that countries understand and measure their own progress. More recently, notable reports such as the Stiglitz-Sen-Fitoussi Report, and the EU's Beyond GDP report, have acted as both a summary of existing ideas around understanding progress, and guidance for how statistical agencies can measure progress with more accuracy. Many national statistical organisations and other statistical bodies have responded to this guidance by creating frameworks to better measure wellbeing and progress for their nation or for comparison between nations.

Throughout this time, the ABS has been measuring progress for Australia through economic, social and environmental indicators and its flagship publication Measures of Australia's Progress. This chapter has explored some of the international initiatives, as well as developments with which the ABS is moving ahead, such as refreshing the MAP product through a large-scale consultation, and through leadership in environmental-economic accounting, economic statistics, household wealth framework development and the measurement of subjective wellbeing. As statistical agencies continue to work together on the international stage, there will be more movement towards refined understanding and better measures of progress.

\section{References}

Australian Bureau of Statistics (1976). Social Indicators, cat. no. 4101.0, ABS website.

Australian Bureau of Statistics (1994), Australian Social Trends, cat. no. 4102.0, ABS website.

Australian Bureau of Statistics (2002), Measuring Australia's Progress, cat. no. 1370.0.

Australian Bureau of Statistics (2005). Informing a Nation: The Evolution of the Australian Bureau of Statistics 1905-2005, cat. no. 1382.0, ABS website. 
Australian Bureau of Statistics (2010-2011), Australian System of National Accounts, cat. no. 5204.0, ABS website.

Australian Bureau of Statistics (2012a). Measures of Australia's Progress -Aspirations for our nation: A conversation with Australians about progress, Consultation report, cat. no. 1370.0.00.002.

Australian Bureau of Statistics (2012b), Measures of Australia's Progress, cat. no. 1370.0.55.001, ABS website

Australian National Development Index (2012). About ANDI, ANDI website, viewed at 01.11.2012.

Bauer, Raymond A ed. (1966). Social Indicators, Cambridge, Mass., London: The MIT Press: 1.

Castles, Ian (1973). 'Economic Growth: Is it worth having?', Treasury Economy Paper, no. 2, Australian Government Publishing Service: Canberra.

The Centre for Quality of Life (2012). Hong Kong Quality of Life Index, viewed 2 March 2012.

European Commission (2009). GDP and Beyond: Measuring progress in a changing world, viewed 25 May 2012.

International Labour Office (2004). Resolution concerning household income and expenditure statistics, Seventeenth International Conference of Labour Statisticians, Geneva, 3 December 2003.

Kuznets, Simon (1934). National income, 1929-1932, $73^{\text {rd }}$ US Congress, $2^{\text {nd }}$ Session, Senate document no. 124: 7.

Michalos A, Smale B, Labonté R, Muharjarine N, Scott K, Moore K, Swystun L, Holden B, Bernardin H, Dunning B, Graham P, Guhn M, Gadermann A, Zumbo BD, Morgan A, Brooker A and Hyman I (2011). The Canadian Index of Wellbeing: Technical Report 1.0, Waterloo, ON: Canadian Index of Wellbeing and University of Waterloo.

Mill, John Stuart (1848). The Principles of the Political Economy, book 4, chapter vi.

Organisation for Economic Co-operation and Development (2011a). Better Life Index, viewed 26 March 2012.

new economics foundation (2010). Measuring our progress: the power of wellbeing, viewed 25 May 2012.

New Zealand Treasury (2011). Working Towards Higher Living Standards for New Zealanders, New Zealand Treasury Paper 11/02, May 2011. 
6. Measuring Progress: The International Context

Office of National Statistics (2011). National Statistician's Reflections on the National Debate on Measuring National Well-being, viewed 25 May 2012.

Organisation for Economic Co-operation and Development (2011b). How's Life? Measuring Well-being, OECD Publishing.

Oxfam Scotland (2012). Oxfam Humankind Index: The New Measure of Scotland's Prosperity, viewed 10 May 2012.

Statistics New Zealand (2009). Key Findings on New Zealand's Progress Using a Sustainable Development Approach: 2008, viewed 16 March 2012.

Stiglitz J, Sen A, Fitoussi J (2009). Report by the Commission on the Measurement of Economic Performance and Social Progress, Commission on the Measurement of Economic Performance and Social Progress.

Swiss Federal Statistical Office (2010). MONET - Key Indicators, viewed 2 March 2012.

The Treasury (2011-12). Strategic Framework 2011-12, Australian Government, The Treasury website.

United Nations (1969). Declaration on Social Progress and Development, Office of the United Nations High Commissioner for Human Rights, Proclaimed by general Assembly resolution 2542 (XXIV), 11 December 1969.

United Nations Development Program (2012). Human Development Index, viewed 29 February 2012.

United Nations Statistical Commission (2001). 'Report of the friends of the Chair of the Statistical Commission', Report of the Human Development Report Office of the United Nations Development Program, Thirty-second session, 6-9 March 2001.

United Nations System Task Team (2012). 'UN System Task Team on the Post 2015 UN Development Agenda: Realizing the future we want for all', Report to the Secretary-General, New York.

Ura K, Alkire S, Zangmo T, Wangdi K (2012). A Short Guide to the Gross National Happiness Index, The Centre for Bhutan Studies: Thimphu. 